\title{
Álvarez Conde, Enrique y López de los Mozos Díaz-Madroñero, Alicia (dirs.), Sanjuán Andrés, Francisco Javier (coord.), Estudios sobre la refor- ma de la Ley Orgánica del Régimen Electoral Ge- neral: la reforma continua y discontinua, Madrid, Instituto de Derecho Público, 2011, 406 pp.
}

El derecho electoral representa uno de los ámbitos más delicados en un ordenamiento democrático, en el que las elecciones periódicas son el máximo momento de manifestación de la voluntad de los ciudadanos: por esto su regulación tiene consecuencias sobre el propio desarrollo de los derechos constitucionales y las reformas que afectan esta disciplina resultan de gran importancia y criticidad política y jurídica.

La elección de la Constitución Española, que remite a una ley orgánica las normas sobre el procedimiento electoral, es el reflejo de dicha relevancia: la mayoría más elevada necesaria para aprobarlas conlleva a la participación de (una parte de) la oposición, alcanzándose así un consenso más amplio. La Ley Orgánica del Régimen Electoral General (LOREG), núm. 5 de 1985, es todavía el centro del derecho electoral: sobre sus últimas modificaciones se centra el volumen dirigido por E. Álvarez Conde y A. López de los Mozos Díaz-Madroñero.

Las reformas explícitas de la LOREG han derivado de trece leyes orgánicas y una sentencia del Tribunal Constitucional, como recuerda L. López Nieto (Reflexiones sobre las reformas electorales en España, pp. 84 y ss.) y han tocado diferentes aspectos, a partir de la extensión del voto a los ciudadanos de la entonces CEE en las elecciones municipales. Sin embargo, algunas de las reformas se debieron a problemáticas específicas del contexto español, como por ejemplo el riesgo de que se 
formasen partidos vecinos a ETA. Al mismo tiempo, existen ámbitos que no han sido nunca sujetos a cambios (el derecho de sufragio pasivo y las incompatibilidades de los parlamentarios, entre otros).

El debate acerca de la necesidad de realizar una reforma amplia se ha desarrollado con gran vehemencia a lo largo de los últimos tres años, ya que los principales partidos (aunque no sólo) proponían expresamente modificaciones de la disciplina electoral en sus programas para las elecciones generales de 2008.

El PSOE (Motivos para creer-Programa electoral, elecciones generales 2008, p. 215 y ss., en www.psoe.es) afirmaba en primer lugar la importancia de un consenso que abarcase todas las fuerzas políticas, por lo cual se empeñaba en evitar transformar este tema en un objeto de contienda. El objetivo era "mejorar la participación de la ciudadanía, no... cambiar el modelo" y para ello se preveían algunas medidas: crear una circunscripción en el exterior para las elecciones de las Cortes (mediante una reforma constitucional); facilitar el voto de las personas con discapacidad; mejorar el ejercicio del sufragio gracias a las nuevas tecnologías; disminuir la posibilidad de publicidad institucional propagandística e instituir una comisión de arbitraje para los debates electorales televisados. El PP (Las ideas claras-Programa de Gobierno 2008, en $w w w . p p . e s)$ incluía a su vez en el programa la creación de una comisión de expertos que analizara y evaluara el sistema electoral tras treinta años de vigencia, para elaborar las propuestas de reforma oportunas (p.47). Además, se proponía facilitar el voto de los ciudadanos residentes en el extranjero, impulsando reformas legislativas y el empleo de medios que permitieran el voto en urna en las representaciones diplomáticas y garantizando también la asistencia ofrecida por las oficinas consulares (p. 306).

La reforma es también consecuencia de un informe presentado por la Comisión de Estudios del Consejo de Estado en 2009, en la que se avanzaban ideas de cambios aún más profundos (al respecto, véanse, por ejemplo, F. Rubio Llorente, P. Biglino Campos, Informe del Consejo de Estado sobre la reforma electoral. Texto del informe y debates académicos, Madrid, CEPC, 2009 y F. Santaolalla López, "Comentario a la reforma electoral propuesta por el Consejo de Estado", Revista de las Cortes Generales, núm. 77, 2009, pp. 63 y ss.). Las finalidades de los cambios propuestos eran básicamente impulsar la participación ciudadana y mejorar la calidad democrática de vida política o el rendimiento de las instituciones. Al informe están dedicados dos estu- 
dios contenidos en el volumen: A. Sánchez Navarro, "El Consejo de Estado y la reforma electoral” (pp. 103 y ss.) y D. Ortega Gutiérrez, "El informe del Consejo de Estado de 24 de febrero de 2009 sobre las propuestas de modificación del régimen electoral general. La apertura de nuestra democracia” (pp. 125 y ss.).

Las leyes orgánicas núms. 2 y 3 de 2011 han aportado, en efecto, modificaciones sustanciales a la disciplina, abarcando aspectos muy variados: desde el censo hasta el voto de los extranjeros residentes, desde las campañas electorales hasta los delitos electorales. En todos y cada uno de estos perfiles profundizan los estudios recogidos en el volumen, ofreciendo un exhaustivo análisis de la reforma y de su alcance. El ensayo introductivo, de E. Álvarez Conde (pp. 21 y ss.), ofrece un primer marco sincrético de las principales novedades, desarrolladas en los demás estudios. El ensayo siguiente, de L. Pegoraro (“¿Quién controla las elecciones? La enseñanza de las nuevas democracias y la lección para Europa”, pp. 35 y ss.), analiza el aspecto del control electoral en un marco comparado, subrayando los elementos que los nuevos constitucionalismos ofrecen a la reflexión europea.

Volviendo a los contenidos de la reforma, la LO núm. 2 ha incidido en primer lugar sobre el censo electoral y ha definido los plazos para comunicar informaciones por parte de ayuntamientos y consulados; además ha aumentado las medidas para evitar empadronamientos masivos y fraudulentos durante el periodo electoral, por ejemplo anticipando el censo cerrado para la elección (véase a F. Díaz Revorio, "La reforma del censo electoral”, pp. 225 y ss.). Otra notable novedad ha afectado el voto de los ciudadanos que viven fuera de España (pueden ejercer su derecho en un consulado o embajada en los últimos tres días de campaña, manteniéndose también el voto por correo: véase el ensayo de M. R. Ripollés Serrano, "La nueva regulación del derecho al voto de los españoles que se encuentran en el extranjero, especial consideración al CERA tras la reforma de la LOREG por la LO 2/2011", pp. 201 y ss.). La situación de los extranjeros que al revés residen en el país ha sido objeto de algunos cambios, aplicables incluso en las elecciones municipales celebradas en mayo de este año (M. R. García Mahamut, "El derecho de sufragio de los extranjeros en España", pp. 161 y ss.).

Por lo que concierne a la campaña electoral (a la que se refiere el ensayo de O. Mateos y de Cabo, "La campaña electoral en la ley orgánica 2/2011: una reforma democratizadora”, pp. 329 y ss., y el de 
E. Aranda Álvarez, "La reforma electoral. Los cambios que afectan a las campañas electorales", pp. 355 y ss.), la intención era disminuir la propaganda electoral en precampaña y por esto se reduce la publicidad política a la sola campaña en sentido estricto (quince días). También la regulación de la financiación electoral es actualizada (véase A. García-Moncó Martínez, "La financiación electoral. Los avales de los partidos”, especialmente, pp. 318 y ss.).

Otro aspecto, aunque "secundario" (así lo define C. Flores Juberías, "Si no puedes eliminarlos, neutralízalos: la cuestión del transfuguismo en la reforma de la LOREG", p. 286) afrontado por esta ley orgánica ha sido el transfuguismo en el cambio de gobierno a nivel municipal, modificándose las condiciones y el procedimiento para la moción de censura contra los alcaldes. En última instancia, se ha procedido a actualizar y cambiar parcialmente las normas relativas a los delitos electorales (G. Martín Martín, "La LOREG y los delitos electorales", pp. 379 y ss.).

La LO núm. 3 de 2011 ha previsto la inelegibilidad de los sujetos condenados por sentencia, aunque no firme, por determinados delitos (rebelión, terrorismo, etcétera) si se les ha conminado la inhabilitación para el ejercicio del derecho de sufragio pasivo o la inhabilitación o la suspensión para empleo o cargo público. En segundo lugar, en la misma se ha afirmado que "las causas de inelegibilidad lo son también de incompatibilidad" y que se consideran incompatibles los candidatos electos en partidos o grupos declarados ilegales posteriormente, con decisión firme. Al mismo tiempo se prohíbe la presentación de candidaturas que "vengan a continuar o suceder la actividad de un partido político declarado judicialmente ilegal y disuelto, o suspendido", según parámetros sustanciales (sobre todos estos aspectos se concentra el ensayo de J. Tajadura Tejada, "La reforma electoral y la ilegalización de partidos políticos: comentario de la LO 3/2011, de 28 de enero, por la que se modifica la LO 5/1985, de 19 de junio, de régimen electoral general", p. 247 y ss.). Se modifican, además, varios aspectos procesales, previéndose entre otras la posibilidad de solicitar la suspensión cautelar de la proclamación de los electos en partidos que podrían ser declarados ilegales. Hay algunas reformas incluso al Código Penal, respecto de algunos delitos relacionados con el ámbito electoral.

Los aspectos modificados tras la aprobación de las dos leyes orgánicas son muchos, como resulta evidente, y por esto la doctrina española se ha dedicado a ellos antes y después de su aprobación (véase por 
ejemplo el número monográfico de 2009 sobre la reforma electoral de la Revista de Derecho Político). Hoy en día, además, se presentan problemáticas ulteriores debido a los avances de la técnica (como el empleo de las nuevas tecnologías, al que está dedicado el estudio de J. Cano Bueso, "Democracia política y representación ciudadana: Internet y las nuevas formas de participación", pp. 141 y ss.) o incluso a los procesos de integración supranacional (R. Arnold, La reforma electoral en el Parlamento europeo, pp. 63 y ss.).

El volumen ofrece así un panorama completo de las modificaciones, de sus antecedentes y justificaciones, dando al lector una idea clara de las soluciones adoptadas. Por esto es un instrumento fundamental para quienes se acercan a la disciplina electoral española deseando adquirir una conciencia crítica y profundizar en el conocimiento de la evolución normativa.

Sabrina Ragone

Doctora en Derecho, Universidad de Pisa y Universidad Carlos III de Madrid. Investigadora de Derecho Público Comparado en la Universidad de Bolonia 